
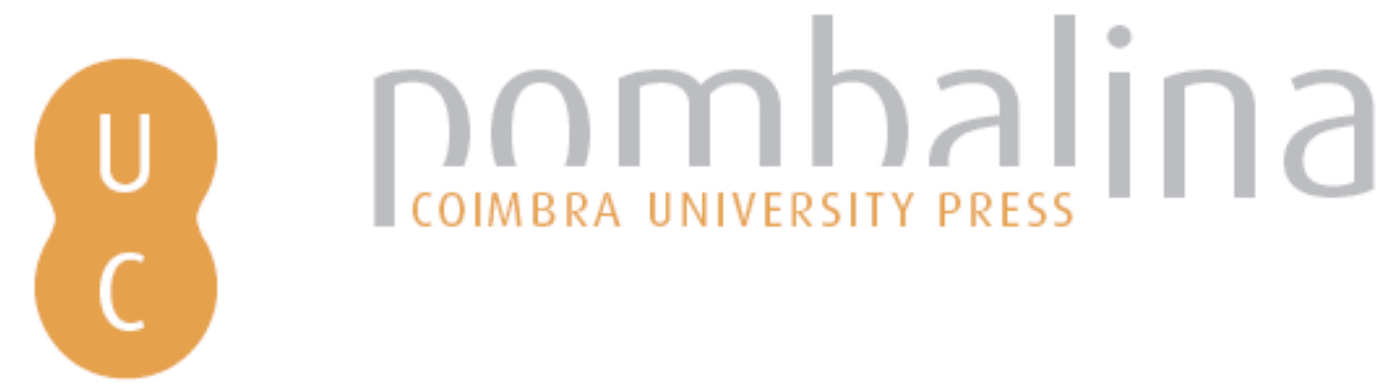

\title{
Concurrent multi-scale physical parametrization of fire-spotting: a study on the role of macro- and meso-scale characteristics of the system
}

Autor(es): $\quad$ Egorova, Vera N.; Trucchia, Andrea; Pagnini, Gianni

Publicado por: Imprensa da Universidade de Coimbra

URL

persistente: URI:http://hdl.handle.net/10316.2/44558

DOI: $\quad$ DOI:https://doi.org/10.14195/978-989-26-16-506_41

Accessed : $\quad$ 26-Apr-2023 11:53:29

A navegação consulta e descarregamento dos títulos inseridos nas Bibliotecas Digitais UC Digitalis, UC Pombalina e UC Impactum, pressupõem a aceitação plena e sem reservas dos Termos e Condições de Uso destas Bibliotecas Digitais, disponíveis em https://digitalis.uc.pt/pt-pt/termos.

Conforme exposto nos referidos Termos e Condições de Uso, o descarregamento de títulos de acesso restrito requer uma licença válida de autorização devendo o utilizador aceder ao(s) documento(s) a partir de um endereço de IP da instituição detentora da supramencionada licença.

Ao utilizador é apenas permitido o descarregamento para uso pessoal, pelo que o emprego do(s) título(s) descarregado(s) para outro fim, designadamente comercial, carece de autorização do respetivo autor ou editor da obra.

Na medida em que todas as obras da UC Digitalis se encontram protegidas pelo Código do Direito de Autor e Direitos Conexos e demais legislação aplicável, toda a cópia, parcial ou total, deste documento, nos casos em que é legalmente admitida, deverá conter ou fazer-se acompanhar por este aviso.

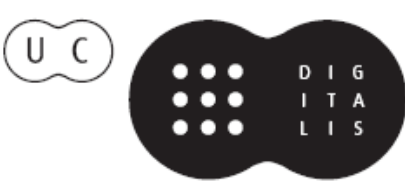




\section{ADVANCES IN}

\section{FOREST FIRE RESEARCH}

\section{8}

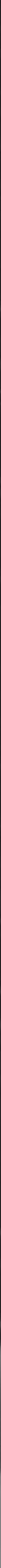




\title{
Concurrent multi-scale physical parametrization of fire-spotting: A study on the role of macro- and meso-scale characteristics of the system
}

\author{
Vera N. Egorova ${ }^{1}$; Andrea Trucchia ${ }^{1,2}$; Gianni Pagnini ${ }^{1,3}$

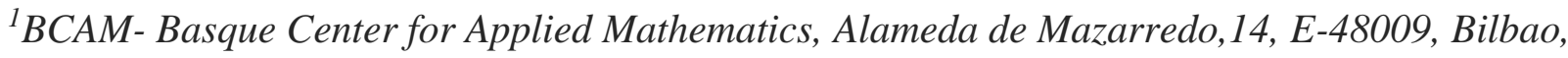 \\ Basque Country, Spain.\{vegorova@bcamath.org, atrucchia@bcamath.org, \\ gpagnini@bcamath.org*\} \\ ${ }^{2}$ Ikerbasque - Basque Foundation for Science, Calle de María Díaz de Haro, 3, E-48013, Bilbao, \\ Basque Country, Spain \\ ${ }^{3}$ University of the Basque Country UPV/EHU, Barrio Sarriena, s/n, 48940, Leioa, Basque \\ Country, Spain
}

\begin{abstract}
The strong impact of wildfires in terms of lives and homes lost and of damage to ecosystems, calls for an urgent improvement in the risk management. The aim of the present research is the improvement of these software codes by proposing a complete physical characterization of fire-spotting within an approach that is ready to be implemented as a post-processing routine of standard outputs. The main feature of the proposed method is that the effects of random fluctuations are included in a way that preserves the existing structure of the operational and industrial codes and can be implemented directly. The operational code WRF-SFIRE have been used to test the proposed post-processing routine. Results show the suitability of the approach for simulating random effects due to turbulent convection and fire-spotting, which are cases not resolved by standard operational codes. Results of simulations including response analysis with test cases are shown and discussed.
\end{abstract}

Keywords: Fire-spotting, Simulation, Multi-scale characteristics

\section{Introduction}

Propagation of a wildfire is a multiscale phenomenon involving processes from the scale of the combustion chemistry to the fire-atmosphere coupling including effects due to the flame geometry (Sullivan, 2017a, 2017b). One of the key aspects of fire propagation is the so-called fire-spotting (Fernandez-Pello, 2017). It occurs when burning embers tear off from the main fuel source and cause new independent ignitions. It accelerates significantly the fire spread causing dangerous consequences and increasing the damage. Moreover, the fire-spotting is a challenging issue in wildfire science due to its unpredictable nature.

Here we study the role for the emergence of fire-spotting phenomena and the ignition of secondary fires of both a macro-scale factor as the atmospheric stability, and of a meso-scale factor as the flame length.

Because of the interactions among scales, we follow a concurrent multiscale modelling that means estimating parameters related to aspects occurring in a very large range of scales and implementing them into the model for the macroscopic fire perimeter, see Figure 1. 


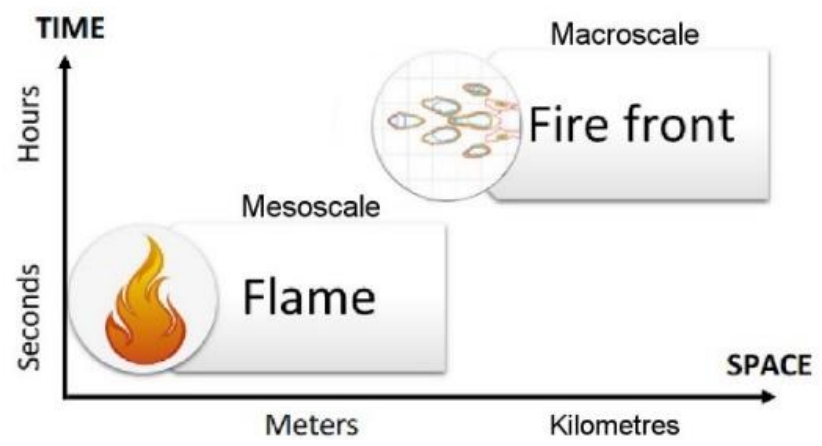

Figure 1 - Multiscale modelling of wildland fires

The adopted modelling approach (Pagnini and Mentrelli, 2014; Kaur et al., 2016) is based on the idea to split the motion of the front into a drifting part and a fluctuating part. The drifting part represents the main front motion as a free boundary problem. Thus, it can be treated by any existing method, for instance, based on the level-set method (LSM) (Sethian and Smereka, 2003) in analogy with WRFSFIRE model (Mandel et al., 2011). The fluctuating part, that is the result of a comprehensive statistical description of the physics of the system and includes the random effects, is here physically parametrized to include turbulent hot-air transport and firebrand landing distance.

The rest of the text is organized as follows. In Section 2 we propose a parametrization of the firebrand-landing distribution including macro-scale and meso-scale parameters. In Section 3 the model is proposed and in Section 4 the response analysis is performed by using the LSM. In Section 5 we show few scenarios obtained by the implementation of the proposed model into the operational code WRF-SFIRE. Conclusions are given in Section 6.

\section{Firebrand landing distribution}

\subsection{Lognormal probability density}

Fire-spotting can be introduced into operational codes as a post-processing routine. Fire-spotting can be describes via the firebrand landing distribution $q(\ell)$, that is here assumed to be lognormal distributed following (Sardoy et al., 2008; Himoto and Tanaka, 2005),

$$
q(\ell)=\frac{1}{\sqrt{2 \pi} \sigma \ell} e^{\frac{-\left(\ln \frac{\ell}{\mu}\right)^{2}}{2 \sigma^{2}}},
$$

where $\mu$ is the ratio between the square of the mean of landing distance $\ell$ and its standard deviation $\sigma$. The parametrisation stated in (Kaur and Pagnini, 2016) is based on the assumption that each firebrand is spherical with constant size. Following Kaur and Pagnini (2016), the lognormal parameters $\mu$ and $\sigma$ in (1) result to be

$$
\mu=H\left(\frac{3 \rho C_{d}}{2 \rho_{f}}\right)^{1 / 2}, \quad \sigma=\frac{1}{z_{p}} \ln \left(\frac{U}{\sqrt{r g}}\right),
$$

where $U$ is the wind speed and $H$ is the maximum loftable height of firebrands, $g$ is gravitational acceleration, $\rho$ is the ambient air mass density, $\rho_{f}$ and $r$ are the density and the radius of the firebrand. The dimensionless ratio

$$
F r=U^{2} /(r g)
$$


known as the Froude number is a measure of the balance between the inertial and the gravitational forces experienced by the burning ember. In terms of the Froude number the standard deviation $\sigma$ can be written as follows

$$
\sigma=\frac{1}{2 z_{p}} \ln F r
$$

In the following we parametrize firebrand landing distribution (1)-(2) taking into account atmospheric stability conditions and the flame characteristics.

\subsection{Macro-scale parametrs}

At the macroscopic scale, fire-spotting is affected by atmospheric conditions. In particular, we plug the depth of the atmospheric boundary layer (ABL), that is related to the atmospheric stability, into the estimation of the smoke-injection height including the uplift against the atmospheric stratification and the plume widening due to entrainment of the surrounding air (Sofiev et al., 2012). Later, we estimate the firebrand-injection height as an approximated lift for inertial particles flowing into the fire plume.

We assume that firebrands lofted by a smoke column are similar to inertial particles moving into a fluid, thus it is found that the maximum loftable height is a fraction of the smoke height $H^{*}$, i.e., the maximum height reached by a smoke particle, here we use $H \simeq 0.4 H^{*}$. According to Sofiev et al. (2012), $H^{*}$ is defined as follows

$$
H^{*}=\alpha H_{A B L}+\beta\left(\frac{I}{P_{f_{0}} \cdot d}\right)^{\zeta} \exp \left(-\frac{\delta N_{F T}^{2}}{N_{0}^{2}}\right),
$$

where $N^{2}$ is the Brünt-Väsäla frequency, sub-index $F T$ means free troposphere, $H_{\mathrm{ABL}}$ is the height of ABL. Note that, according to Sofiev et al. (2012), the parameters are chosen as follows: $\alpha<1, \beta>$ $0, \zeta<0.5$ and $\delta \geq 0$.

Atmospheric conditions affect both the firebrand landing distribution and the turbulent diffusion coefficient $\mathcal{D}$, that is estimated by the following formula (Kaur et al., 2016)

$$
\mathcal{D} \simeq \chi(0.1 R a-1)^{\beta \mathcal{D}}, \quad R a=\gamma_{\mathcal{D}} \Delta T g H_{A B L}^{3} v^{-1} \chi^{-1},
$$

where $\chi$ is the thermal diffusivity of the air at ambient temperature, $R a$ is the Rayleigh number, $\gamma_{\mathcal{D}}$ is the thermal expansion coefficient, $\Delta T$ is the temperature difference between the bottom and the top of the convective cell, and the vertical dimension of the convection cell is $H_{\mathrm{ABL}}, v$ is the kinematic viscosity. Parameter $\beta_{\mathcal{D}}$ is the exponent of the power law relating the Nusselt number $N u$ and the Rayleigh number $R a$, i.e., $N u=0.1 R a^{\beta_{\mathcal{D}}}$ (Niemela et al., 2000; Niemela and Sreenivasan, 2006). Previous experimental results suggested $\beta_{\mathcal{D}} \approx 2 / 7$ instead of $1 / 3$ ( Wu and Libchaber, 1992).

\subsection{Meso-scale parameters}

Let us consider the geometrical model of the flame, as it is presented in Figure 2. It is natural that the flame characteristics are strongly affected by the wind and the fire intensity. Moreover, it can be easily found that the flame length $L_{f}$ and the flame height $H_{f}$ are connected by the following trigonometric relation

$$
H_{f}=L_{f} \cos \theta \text {, }
$$

where $\theta$ is the flame angle, or flame tilt. Thus, in the no-wind case, $H_{f}=L_{f}$, since $\theta=0$. 


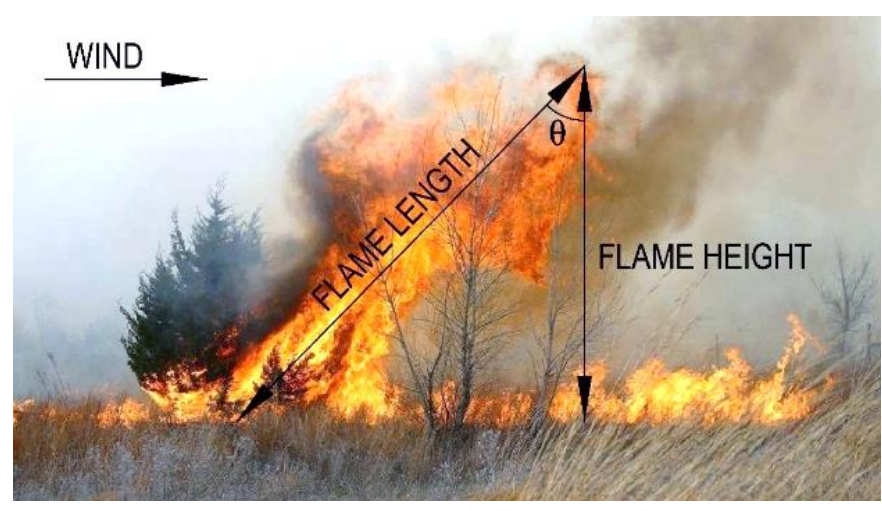

Figure 2 - Flame geometry in real wildland fire.

The flame height is leaded by the buoyancy and by the mean wind. Adopting the formula proposed by Albini (1981), one gets

$$
H_{f}=\left(\frac{1}{2 g\left(\rho c_{p} T_{a}\right)^{2}}\right)^{1 / 3} \mathrm{I}^{2 / 3} \cos \theta,
$$

where $c_{p}$ is the specific heat of fuel, I is the fireline intensity and the ambient temperature is denoted by $T_{\mathrm{a}}$.

Inserting (8) into (7), the flame length can be derived in term of the fireline intensity as follows

$$
L_{f}=\left(\frac{1}{2 g\left(\rho c_{p} T_{a}\right)^{2}}\right)^{1 / 3} \mathrm{I}^{2 / 3} .
$$

In order to take into consideration the flame length (9), the maximum travel distance for a spherical firebrand used in (1) is written in the following form (Wang, 2011):

$$
\ell_{\max }=H\left(\beta_{2} \cot \theta+U\left(\frac{3 \rho C_{d}}{2 \rho_{f} r g}\right)^{2}\right),
$$

where $\beta_{2}=0.7$ is a correction factor. Note that the angle of flame can be estimated by an empirical correlation $\cot \theta=1.35 U\left(g L_{f}\right)^{-1 / 2}$.

According to Kaur et al. (2016), the landing distance can be represented by the $p^{\text {th }}$ percentile of the lognormal distribution, such that

$$
\ell_{\max }=\mu e^{z_{p} \sigma}
$$

The value that corresponds to this $p^{\text {th }}$ percentile can be defined in terms of $\kappa$ - the ratio between the maximum and minimum travel distance and the Froude number as follows:

$$
z_{p}=\frac{\ln F r}{\sqrt{2 \ln ^{\kappa} / F r}} \text {. }
$$

Thus, from (10) and (11) one gets

$$
\sigma=\frac{1}{z_{p}} \ln \left(F r^{1 / 2}+\beta_{3}\left(\frac{2 \rho_{f} r g U^{2}}{3 \rho C_{d} g L_{f}}\right)^{1 / 2}\right),
$$

where $\beta_{3}=0.945$ is a correcting factor from Wang (2011), and the flame length $L_{f}$ is defined by general formula (9). 


\section{Model description}

The motion of wildfire front can be split into a drifting part and a fluctuating part. After the splitting, the drifting part can be treated by any existing operational code such as WRF-SFIRE (Mandel et al., 2011). The fluctuating part, that is independent of the drifting part, describes the effects of turbulence and fire-spotting as random phenomena and they are implemented into the model through a postprocessing routine (Pagnini and Mentrelli, 2014; Kaur et al., 2016). Here we provide a short description of this model.

For a given computational domain $S$ the fire front contour is represented by a closed curve $\Gamma$. The region bounded by $\Gamma$ is denoted by $\Omega(t)$ and represents the burnt area at time $t$. Let us introduce an indicator function $\varphi(x, t)$ :

$$
\varphi(x, t)= \begin{cases}1, & \text { if } x \in \Omega(t), \\ 0, & \text { otherwise. }\end{cases}
$$

In order to treat the fluctuating part of the front motions, the following method is used. The random front contour caused by the turbulence and fire-spotting phenomena, can be defined by the effective indicator function (Pagnini and Mentrelli, 2014):

$$
\varphi_{e}(x, t)=\int_{s} \varphi(\bar{x}, t) f(x ; t \mid \bar{x}) d \bar{x}=\int_{\Omega(t)} f(x ; t \mid \bar{x}) d \bar{x},
$$

where $f(x ; t \mid \bar{x})$ is the probability density function (PDF) that accounts for turbulence and firespotting effects. Note that the point is labelled as burnt, if $\varphi_{e}(x, t)$ exceeds a threshold value $\varphi_{e}^{t h}$.

Denoting by $\omega$ the angle between the wind direction and the vector from some point of the computational domain to the point where the PDF is computed, the minimum acceptable for firespotting angle $\omega_{0}$ has to be established as follows

$$
\cos \omega_{0}=\max \left\{\frac{1}{\kappa}, F r^{-\frac{1}{2}}\right\},
$$

where $\kappa$ is the ratio between the maximum and minimum travel distance of a firebrand.

Taking into account (16) and assuming that the downwind phenomenon of fire-spotting is given by the turbulence and fire-spotting, the random process handled by $f(x ; t \mid \bar{x})$ in $(15)$ is defined as follows

$$
f(x ; t \mid \bar{x})=\left\{\begin{array}{cc}
\int_{0}^{\infty} G(x-\bar{x}-\ell n ; t) q(\ell) d \ell, & \text { if } \cos \omega>\cos \omega_{0}, \\
G(x-\bar{x} ; t), & \text { otherwise. }
\end{array}\right.
$$

where $q(\ell)$ is a lognormal distribution (1) with parameters $\mu$ and $\sigma_{\omega}$, given in (2) and (4), and $\cos \omega_{0}$ is defined by (16).

As it is mentioned above, the point is marked as burned if the effective indicator exceeds the threshold value $\varphi_{e}^{\text {th }}$. However, there exists an additional criterion associated with an ignition delay due to pre-heating action of the hot air or to the landing of firebrands. This delay is considered as a heating-beforeburning mechanism due to the hot air (Pagnini and Massidda, 2012a, 2012b) and it can be generalized to include fire-spotting (Pagnini and Mentrelli, 2014). Since the fuel can burn because of two pathways - hot-air heating and firebrand landing, the resistance analogy suggests that the resulting ignition delay can be approximatively computed as resistances acting in parallel. Let $\tau_{h}$ and $\tau_{f}$ be the ignition delay due to hot air and firebrands landing, respectively, the joint ignition delay $\tau$ is

$$
\frac{1}{\tau}=\frac{1}{\tau_{h}}+\frac{1}{\tau_{f}}=\frac{\tau_{h}+\tau_{f}}{\tau_{h} \tau_{f}}
$$

The heating-before-burning mechanism is depicted as the persistence in time of the effective fire front, i.e., 


$$
\psi(x, t)=\int_{0}^{t} \varphi_{e}(x, \eta) \frac{d \eta}{\tau}
$$

where $\psi(x, t)=0$ corresponds to the unburned initial condition, and ignition at the point $x$ at the moment $t$ occurs, if $\psi(x, t)=1$.

\section{Response analysis}

In this section,we show the effects of the macro- and meso-scale parameters described above by simulations done performed with the LSM that is at the basis of WRF-SFIRE. All the factors and parameters, except those that are to be studied, are fixed. We set a wind speed $U=4.47 \mathrm{~ms}^{-1}$, that corresponds to the average wind speed in Madrid during 2017 (https://www.worldweatheronline.com/madridweather-averages/madrid/es.aspx), and fire intensity $I_{f}=20 \mathrm{MWm}^{-1}$. The changes in the values of $H_{\mathrm{ABL}}$ are reflected into the changes of the values of the maximum travel distance of firebrands $\ell_{\max }$ as well as into the values of the turbulent diffusion coefficient $\mathcal{D}$, see Table 1 . From (6) we have that the turbulent diffusion coefficient depends on $H_{\mathrm{ABL}}$ with the third power and the resulting changes affects strongly the propagation of the fire with an important effect on the merging of the secondary fires generated by the fire-spotting. In fact, during stable conditions a larger number of fires with respect to unstable conditions is observed but at the same time a lower burned area is computed, showing that in unstable conditions the turbulent heat transport is stronger with the double effects of a faster fire propagation and a more efficient merging.

Table 1 - Effects of atmospheric stability on the fire-spotting parameters.

\begin{tabular}{|l|rrrr|rrr|}
\hline & \multicolumn{3}{|c|}{ Case 1: Stable } & \multicolumn{3}{c|}{ Case 2: Unstable } \\
\hline$H_{A B L}[\mathrm{~m}]$ & 100 & 200 & 400 & 800 & 1000 & 1200 & 2000 \\
$\mu[\mathrm{m}]$ & 4.0325 & 4.3879 & 5.0985 & 6.5198 & 7.2304 & 7.9411 & 10.7836 \\
$\mathcal{D}\left[\mathrm{m}^{2} \mathrm{~s}^{-1}\right]$ & 0.0533 & 0.0995 & 0.1858 & 0.3467 & 0.4238 & 0.4993 & 0.7908 \\
\hline
\end{tabular}

Figure 3 shows the total number of burned points at different times for different atmospheric conditions. What is evident from the simulations is that, after an initial period of quiescence with no visible contributions, the burned area rapidly increases as a power law. This power law seems to hold at stable atmospheric conditions, but the quiescence period ends first in unstable conditions such that the burned area during unstable conditions is always larger than during stable conditions.

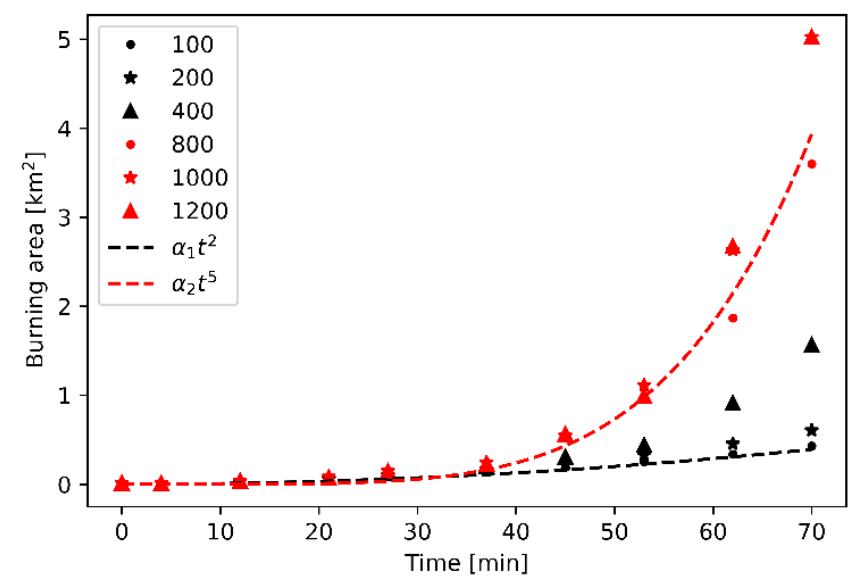

Figure 3 - A comparison of the burned area in different time moments in stable (black) and unstable (red) atmospheric boundary conditions for various $\mathrm{H}_{A B L}$. 
In order to check if the rapid increasing of the burned area is mainly due to turbulence or firespotting we performed a series of simulations with fixed diffusion coefficient $\mathcal{D}$, i.e., independent of the atmospheric conditions. The results for stable $\left(H_{A B L}=100 \mathrm{~m}\right)$ and unstable $\left(H_{A B L}=1000 \mathrm{~m}\right)$ atmospheric conditions are shown in Figure 5. All the parameters are set equal to the previous simulations, but with fixed $\mathcal{D}=0.0387 \mathrm{~m}^{2} \mathrm{~s}^{-1}$. Note that this fixed value of $\mathcal{D}$ is less than any other value followed by the dependency on the $H_{A B L}$. Fire front propagates in the same way in both atmospheric conditions, displaying an equal number of secondary fires and equal burned area (see Figure 4). Thus, the atmospheric conditions affect the propagation of wildfires through the heat turbulent transfer. In particular, during unstable conditions we observe that turbulence pushes the front resulting into a faster propagation causing an increasing of the burned area and a more rapid merging of independent fires such that during unstable conditions the number of independent fires is less than during stable conditions in spite of the fact that the burned area is larger.

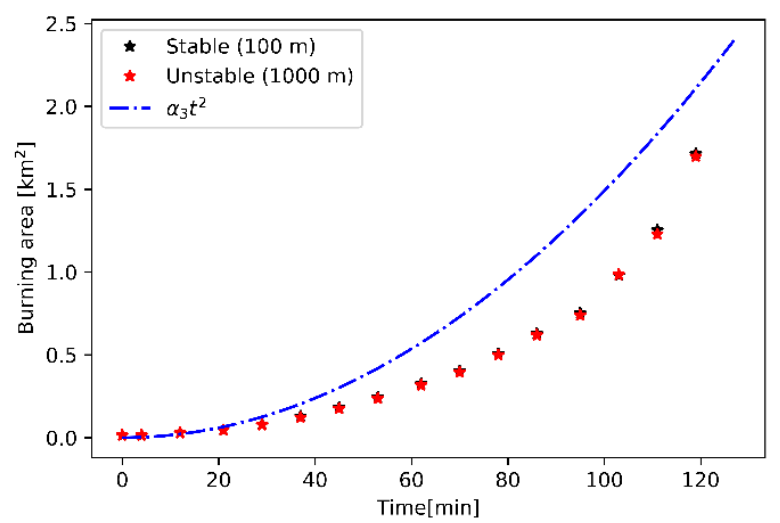

Figure 4 - A comparison of the total burning area in time in stable (black) and unstable (red) atmospheric boundary conditions in simulations with fixed diffusion coefficient $\mathcal{D}=0.0387 \mathrm{~m}^{2} \mathrm{~s}^{-1}$.

Now, let us study the impact of meso-scale factors, such as flame geometry. In formulation of the flame length $L_{f}=\beta_{0} I_{f}^{\beta_{1}}$, that in the case $\beta_{1}=2 / 3$ can be written in form (9), empirical values of $\beta_{0}$ proposed by various authors are given in Table 2 . We set the diffusion coefficient $\mathcal{D}=0.4238 \mathrm{~m}^{2} \mathrm{~s}^{-1}$, that corresponds to $H_{A B L}=1000 \mathrm{~m}$.

Table 2 - Empirical parameters $\beta_{0}$ and corresponding values of $\sigma$.

\begin{tabular}{|l|c|c|}
\hline References & $\beta_{0}$ & $\sigma$ \\
\hline Fons, 1963 & 0.1270 & 5.846 \\
Anderson et al. (Douglas-fir slash), 1966 & 0.0447 & 6.191 \\
Wang, 2011 & 0.0264 & 6.415 \\
Butler, 2004 & 0.0175 & 6.615 \\
\hline
\end{tabular}

The flame length does not affect to $\mu$, thus, $\mu=8.419$ is defined for the set of parameters independently of the chosen formulation of the flame length. Different values of $\sigma$ that correspond to various empirical values $\beta_{0}$ are collected in Table 2 as well. Decreasing factor $\beta_{0}$ leads to increasing value of the standard deviation $\sigma$. In fact, smaller flames produce smaller firebrands, i.e. the shortdistance spotting takes place with further merging and propagating as a joint fire front. However, fire propagation with higher flames is characterised by the long-distance spotting that occurs later, but there is no merging of secondary fires.

Smaller flame length leads to the short-distance spotting, usually, merging of spot-fires. It occurs in real life in many types of fuel and at any fire intensity. These spot-fires may generate new fire- 
spotting, that results in a very fast-moving flaming zone (see Figure 5, the solid line represents the burning area growth in the case of $\beta_{0}=0.127$, when the fire-spotting occurs.

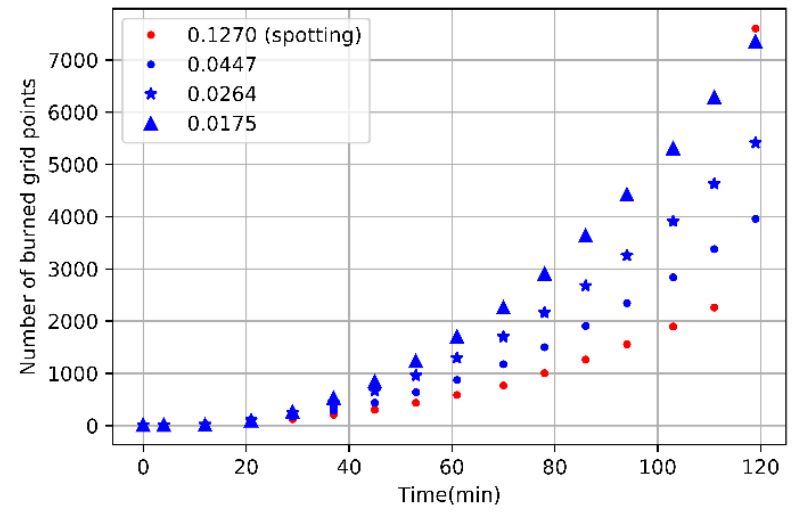

Figure 5 - Burning area with respect to time for various Bo in flame length formulation.

\section{Implementation into WRF-SFIRE}

In order to make the presented model useful for the point of view of the practitioners, it is strongly advised its implementation into full fledged operational codes. Equations (14) - (19) have been implemented in the framework of WRF-SFIRE simulator (Coen et al., 2012; Mandel et al., 2014).

We recall that the wildland fire behavior module WRF-SFIRE is fully integrated into a well known public domain numerical weather prediction model Weather Research and Forecasting (WRF) (Skamarock et al., 2008). The fire module is a surface fire behaviour model that adopts a two-way coupling with the atmospheric model. That is, near-surface winds from the atmospheric model are interpolated to a finer fire grid and are used, with fuel properties and local terrain gradients, to determine the fire's spread rate and direction used for the front propagation routines by the means of the LSM. Fuel consumption, in turn, releases sensible and latent heat fluxes into the atmospheric model's lowest layers, playing a role in boundary layer circulations. Recently, the model has been coupled with a fuel-moisture model, and chemical transport of emissions (WRF Chem) that contribute more and more to the close binding between forest fires and atmospheric observables. The interactions between different modules of the WRF model are shown in Figure 6.

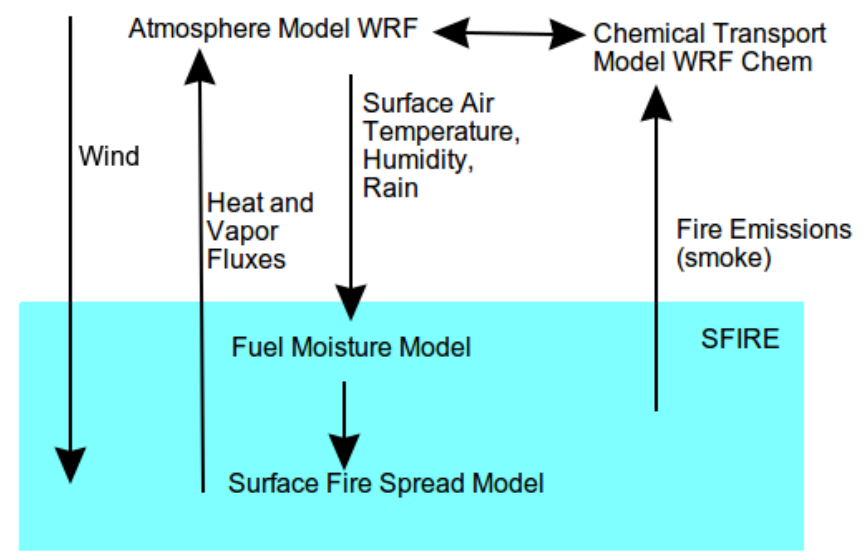

Figure 6 - WRF model

The results of the implementation of the proposed post-processing routine to the WRF-Sfire model are presented in Figures 7-9 at the different times. The main difference to the previous simulations is that fire-spotting parameter $\sigma$ is a space field due to the computed wind field that varies in space and 
time, see Figures 7-9 (a). In Figures 7-9 (b) and (c) the wind horizontal components are plotted, in Figure 7-9 (d) - the squared norm of the wind velocity.

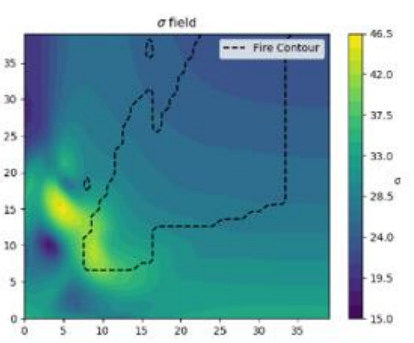

a)

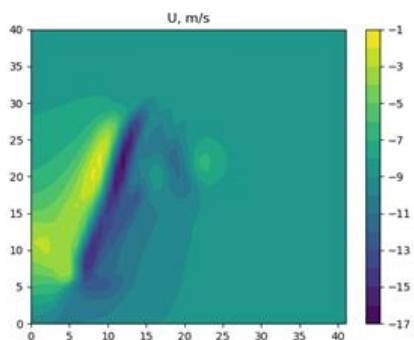

b)

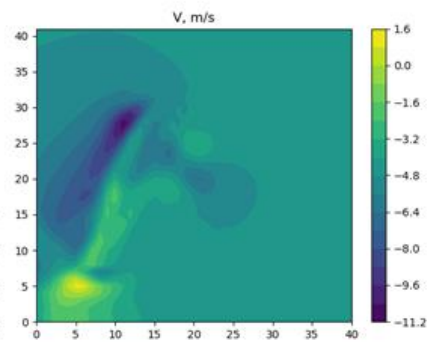

c)

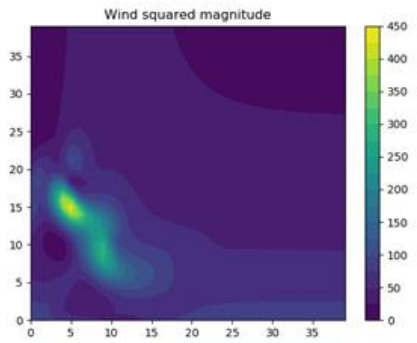

d)

Figure 7 - Space fields of (a) fire-spotting parameter $\sigma$, (b) horizontal and (c) vertical wind components, (d) the squared norm of the wind velocity.

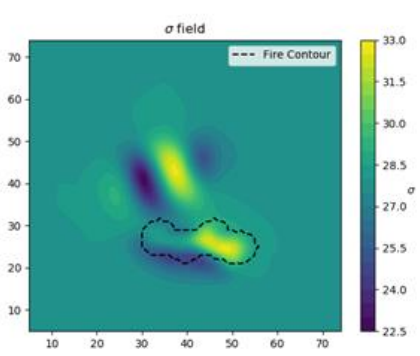

a)

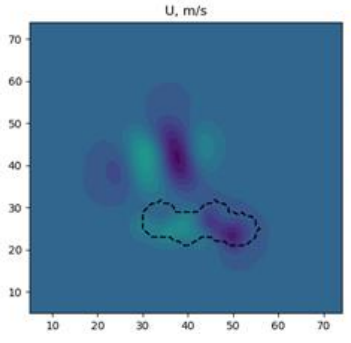

b)
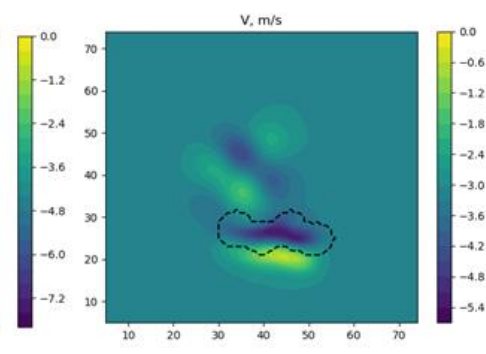

c)

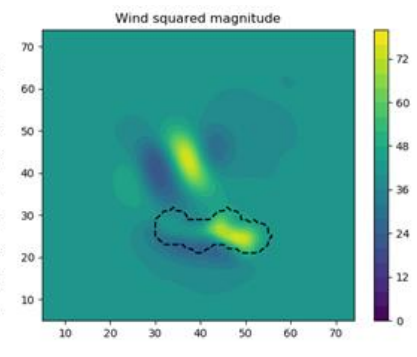

d)

Figure 8 - Space fields of (a) fire-spotting parameter $\sigma$, (b) horizontal and (c) vertical wind components, (d) the squared norm of the wind velocity after 20 minutes of burning.

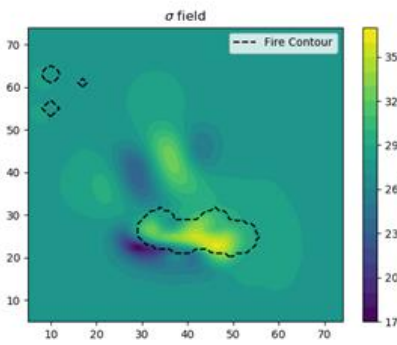

a)

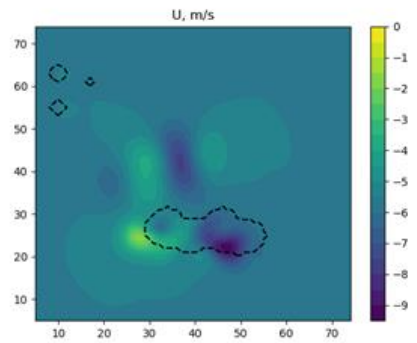

b)

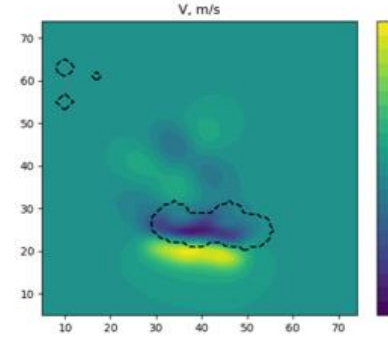

c)

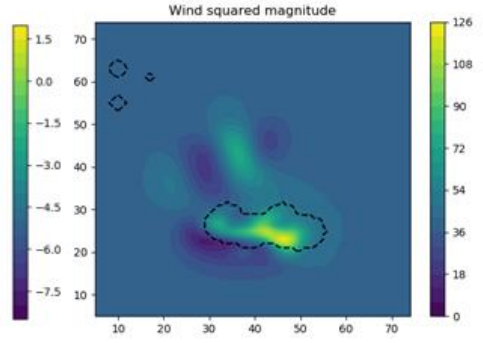

d)

Figure 9 - Space fields of (a) fire-spotting parameter $\sigma$, (b) horizontal and (c) vertical wind components, (d) the squared norm of the wind velocity after 20 minutes of burning.

\section{Conclusion}

The proposed fire-spotting model is based on the firebrand landing lognormal distribution with two parameters $\mu$ and $\sigma$. The response analysis to the parameters has been performed by using the LSM for test cases. Parameter $\mu$ is mainly related to the atmospheric stability conditions taking into account factors as wind speed, ambient air temperature and fire intensity. These ambient parameters affect slightly the firebrand landing distribution, but are found to be significant for effect of turbulent heat transfer on the fire-front propagation. Parameter $\sigma$ takes into account the flame geometry and the surround vegetation. It is shown that small flames provoke short-distance fire-spotting, that leads to the soon merging with the main fire front. Large flames provoke long-distance spotting. Thus, in such 
case the risk and damage increase due to the acceleration of the fire spread. The vegetation feeds the fire and it affects the fire intensity and, consequently, the flame length.

Furthermore, the propose parametrization of fire-spotting has been implemented into the operational code WRF-SFIRE and simulations in this realistic scenarios have been performed.

\section{Acknowledgement}

The research is supported by the Basque Government through the BERC 2018-2021 program and by the Spanish Ministry of Economy and Competitiveness through BCAM Severo Ochoa excellence accreditation SEV-2013-0323 and through project MTM2016-76016-R "MIP" and by the PhD grant "La Caixa 2014".

\section{References}

Albini FA (1981) A model for the wind-blown flame from a line fire. Combustion and Flame 43, 155174.

Coen JL, Cameron M, MichalakesJ, Patton EG, Riggan PJ, Yedinak KM (2012) WRF-Fire: coupled weather-wildland fire modeling with the weather research and forecasting model. Journal of Applied Meteorology and Climatology 52, 16-38.

Fernandez-Pello AC (2017) Wildland fire spot ignition by sparks and firebrands. Fire Safety Journal 91, 2-10.

Himoto K, Tanaka T (2005) Transport of disk-shaped firebrands in a turbulent boundary layer. In 'The Eighth International Symposium on Fire Safety Science, 1823 September 2005, Beijing, China' (Eds Gottuk D, Lattimer B), 433-444.

Kaur I, Mentrelli A, Bosseur F, Filippi JB, Pagnini G (2016) Turbulence and fire-spotting effects into wild-land fire simulators. Communications in Nonlinear Science and Numerical Simulation 39, 300-320.

Kaur I, Pagnini G (2016) Fire-spotting modelling and parametrisation for wildland fires. In 'Proceedings of the 8th International Congress on Environmental Modelling and Software (iEMSs2016); Toulouse, France, 10-14 July (2016)’ (Eds Sauvage S, Sánchez-Pérez JM, Rizzoli AE), 384-391 (ISBN: 978-88-9035-745-9)

Mandel J, Amram S, Beezley JD, Kelman G, Kochanski AK, Kondratenko VY, Lynn BH, Regev B, VejmelkaM (2014) Recent advances and applications of WRF-SFIRE, Natural Hazards and Earth System Sciences 14, 2829-2845.

Mandel J, Beezley JD, Kochanski AK (2011) Coupled atmosphere-wildland fire modeling with WRF 3.3 and SFIRE 2011. Geoscientific Model Development 4, 591-610.

Niemela JJ, Skrbek L, Sreenivasan KR, Donnelly RJ (2000) Turbulent convection at very high Rayleigh numbers, Nature 404, 837-840.

Niemela JJ, Sreenivasan KR (2006) Turbulent convection at high Rayleigh numbers and aspect ratio 4. Journal of Fluid Mechanics 557, 411-422.

Pagnini G, Massidda L (2012a) The randomized level-set method to model turbulence effects in wildland fire propagation. In 'Modelling Fire Behaviour and Risk. Proceedings of the International Conference on Fire Behaviour and Risk. ICFBR 2011, Alghero, Italy, October 4-6 2011, 2012' (Eds Spano D, Bacciu V, Salis M, Sirca C), 126-131 (ISBN 978-88-904409-7-7)

Pagnini G, Massidda L (2012b) Modelling turbulence effects in wildland fire propagation by the randomized level-set method, Tech. Rep. 2012/PM12a, CRS4, Pula (CA), Sardinia, Italy, revised version: 
http://publications.crs4.it/pubdocs/2012/PM12a/pagnini_massiddalevelset.pdf and arXiv:1408.6129 (July 2012)

Pagnini G, Mentrelli A (2014) Modelling wildland fire propagation by tracking random fronts. Natural Hazards and Earth System Sciences 14, 2249-2263.

Sardoy N, Consalvi J, Kaiss A, Fernandez-Pello A, Porterie B (2008) Numerical study of ground-level distribution of firebrands generated by line fires. Combustion and Flame 154, 478-488.

Sethian JA, Smereka P (2003) Level set methods for fluid interfaces. Annual Review of Fluid Mechanics 35, 341-372.

Skamarock WC, Klemp JB, Dudhia J, Gill DO, Barker DM, Duda MG, Huang XY, Wang W, Powers JG (2008) A Description of the Advanced Research WRF Version 3. NCAR Technical Note NCAR/TN-475+STR, doi:10.5065/D68S4MVH

Sofiev M, Ermakova T, Vankevich R (2012) Evaluation of the smoke-injection height from wild-land fires using remote-sensing data. Atmospheric Chemistry and Physics 12, 1995-2006.

Sullivan AL (2017a) Inside the inferno: Fundamental processes of wildland fire behaviour. Part 1: Combustion chemistry and heat release. Current Forestry Reports 3, 132-149.

Sullivan AL (2017b) Inside the inferno: Fundamental processes of wildland fire behaviour. Part 2: Heat transfer and interaction. Current Forestry Reports 3, 150-171.

Wang HH (2011) Analysis on downwind distribution of firebrands sourced from a wildland fire. Fire Technology 47, 321-340.

Wu XZ, Libchaber A (1992) Scaling relations in thermal turbulence: The aspect-ratio dependence. Physical Review A 45, 842-845. 